\title{
Preparation of Ancient Pottery Samples for Electron-Beam Characterization
}

\author{
James H. Steele Jr. Ph.D. Consultant, 2019 Nova Road, Pine, CO 80470
}

The examination of microstructure and identification of micro-constituents in ancient pottery samples via an electron-beam instrument requires that polished cross sections of samples be prepared. Application of the technique of liquid metal impregnation under pressure, originally described by Rose and deRoos[1], and recently illustrated by Steele[2,3] for a variety of porous materials, is extremely useful for mounting porous pottery samples for electron-beam examination. Mounting is carried out using a mounting press with o-rings to allow containment of the low melting liquid metal under pressure, as illustrated by the diagram shown as Fig.1. Open porosity with access throats larger than about $10 \mathrm{~nm}$ can be filled using an applied pressure of $10 \mathrm{ksi}$. Filling of the open porosity with a low melting liquid metal, such as Cerrotru ( $42 \% \mathrm{Bi} / 58 \% \mathrm{Sn}$ ), at $145^{\circ} \mathrm{C}$ yields a mounted sample that can be mechanically polished via standard methods without pull outs or other artifacts. In addition the sample can be argon-ion etched to reveal microstructural features that might not be observable using atomic number contrast from backscatter imaging. Coating of the final polished and etched surface with carbon may not be necessary for backscatter imaging and EDS analysis of the micro-constituents.

An example of the microstructure of a pottery sherd from an ancient pueblo site in northern NM near Puye cliff dwellings is shown by the inverted backscatter micrographs in Figs. 2 and 3. These micrographs are backscatter electron images of a mechanically polished sherd that are shown with inverted contrast for purposes of extending the contrast of the solid constituents and having the pores viewed as a black phase. Provenance of the sherd, which would include other identification techniques, such as thickness, shape, and markings, was not considered in this examination. It is thought that the pueblo site from which the sherd was obtained dated from that of the nearby Puye site, which was about 1400-1500AD. The microstructure consists of large filler particles, which appear to be some type of ground silicates. These were probably derived from the "tuff" that abounds on the Pajarito plateau region where many pueblo ruins are found. The continuous clay phase that binds the filler particles into the mass of the pottery microstructure appears to consist of two distinct phases, which is consistent with a partial transformation to mullite that occurs during firing, as suggested by $x$-ray diffraction results on other samples. The porosity is readily identified as the dark phase filled with the liquid metal (Bi-Sn alloy). Also cracks in the pottery sample can be readily identified as they have also been filled with liquid metal under pressure.

\section{References}

[1] E.T. Rose, and L.F. DeRoos, Microstructural Science, Vol. 1, Elsevier (1974) 275.

[2] J.H. Steele Jr., Microsc. Microanal. 8 (Suppl. 2) (2002) 1248CD.

[3] J.H. Steele Jr., Microsc. Microanal. 8 (Suppl. 2) (2002) 1268CD. 
Fig.1 Schematic diagram of mounting press adapted with o-rings for containment of low melting liquid metal under pressure. The mounting procedure involves heating Above the liquidus of the alloy, and then Applying pressure up to $10 \mathrm{ksi}$, and holding the pressure while cooling the mounting cylinder.

Fig. 2 Inverted backscatter image of a pottery section. The large temper particles (bright), which are silicates, are readily observed. The dark regions are the continuous pore structure, which has been filled with liquid Bi-Sn alloy during the mounting. The clay matrix with some planar mica particles can also be observed.

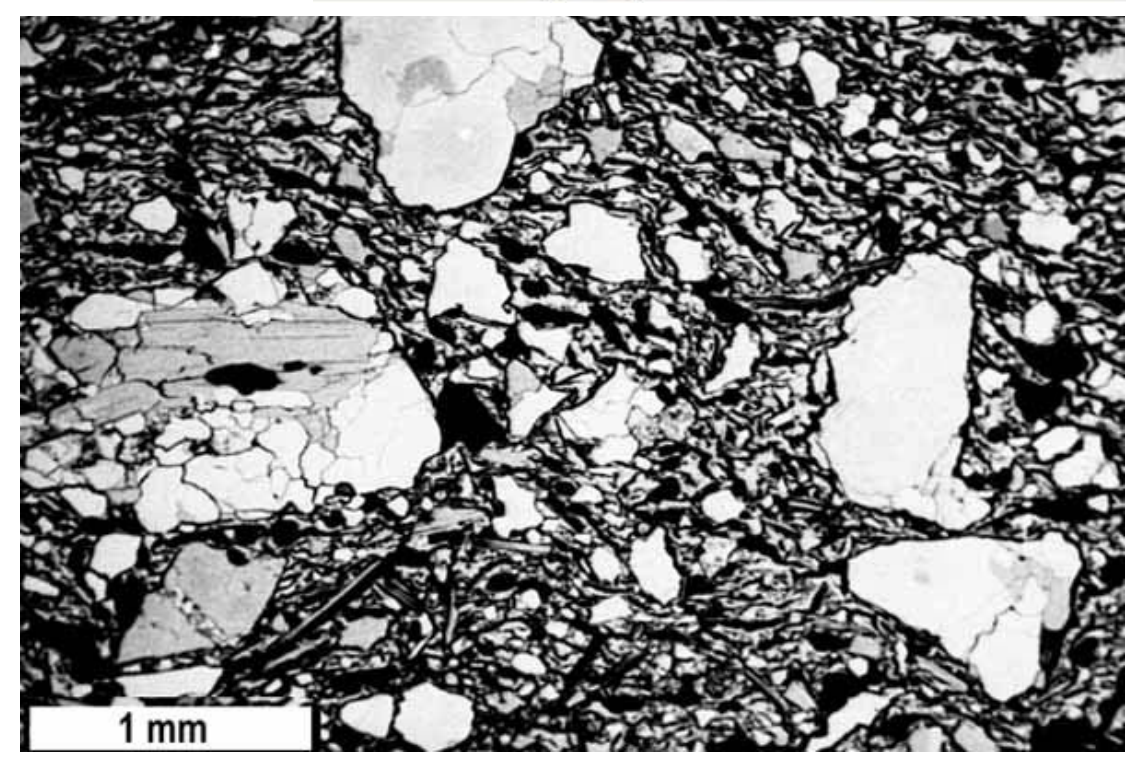

Fig. 3 A higher magnification inverted backscatter image of the pottery section showing the clay matrix and porosity (dark). The mottled appearance of the clay matrix is interpreted as showing partial transformation of the clay to mullite during its original firing. Note that EDS analyses of the constituents was not conducted in this study.

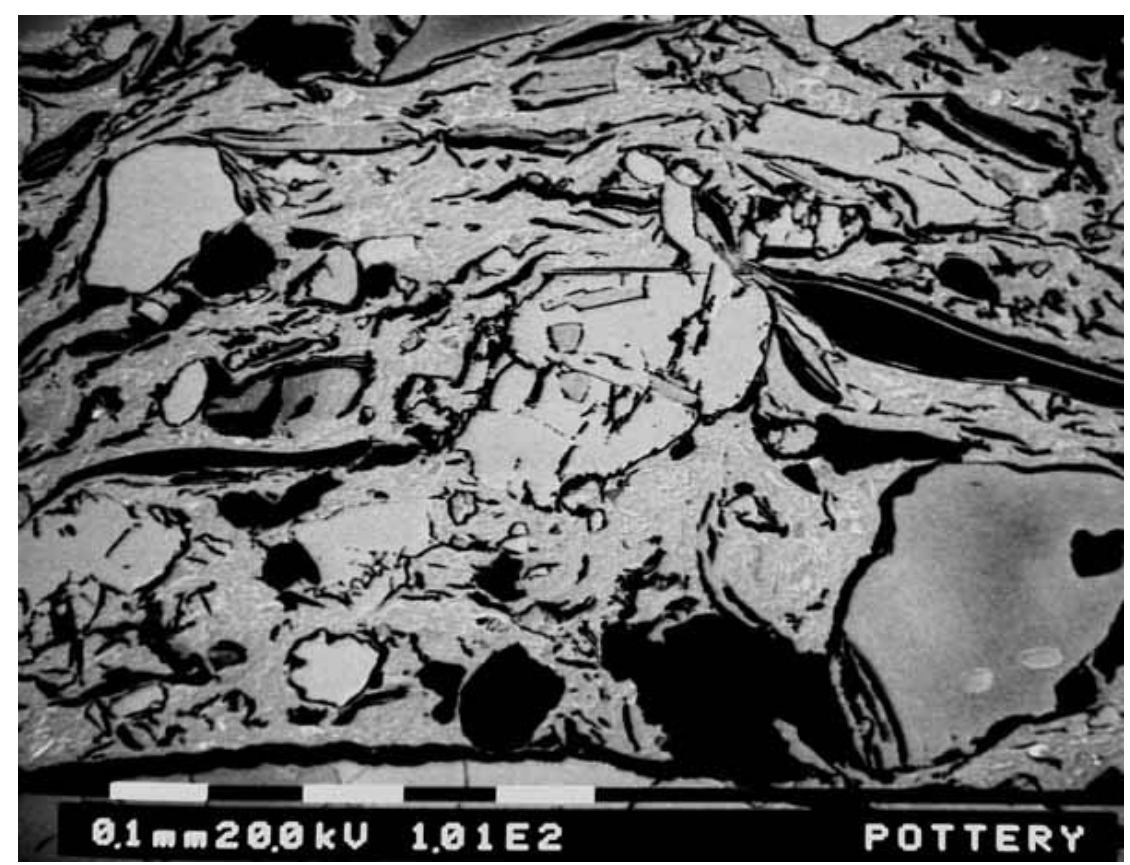

